Great expectations. An analysis of child protection cases concerning immigrant children in Italy as a discursive practice
(C) The Author(s) 2016

Reprints and permissions: sagepub.co.uk/journalsPermissions.nav DOI: I0.1 I77//4733250I6676336 journals.sagepub.com/home/qsw

\title{
Fabio Dovigo
}

Bergamo University, Bergamo, Italy

\begin{abstract}
The paper aims to highlight the role and impact of written documents in managing child protection cases concerning immigrant children and their families in Italy. Analyzing documentation through the lens offered by Foucault's notion of writing as a discursive rite oriented toward the reproduction of social norms, we examined, in depth, eight immigrant children's cases that were handled by welfare services. Reports from practitioners such as social workers, youth workers, psychologists, counsellors, and legal advisors were examined to understand how the piling up of documentation, which is supposed to be neutral and unbiased, concurs to continuously redefine the boundaries between cultural inclusion and exclusion and reassert the common definition of normality. Moreover, we offer suggestions for how developing a reflexive attitude toward the use of documents could help practitioners to promote a more culturally sensitive approach to managing child protection.
\end{abstract}

\section{Keywords}

Cultural diversity, reflexivity, storytelling, child protection, documentation analysis

\section{Literature review and research aims}

Child maltreatment is a well-known public health and societal problem in the European Region (Sethi et al., 2013; Davies and Ward, 2012). In Italy, the number of children under 17 living away from their families has increased from 33.042 in 1999 to 39.698 in $2010(+20 \%)$. Over a fifth of them are immigrant children, often unaccompanied. Data show that on average most children spend

\section{Corresponding author:}

Fabio Dovigo, Bergamo University, 3p.zza S. Agostino, 24129 Bergamo, Italy.

Email: dovigo@unibg.it 
20 months in one of the nearly 3000 Italian reception centres, each case being looked after by a large group of practitioners, including youth workers, social workers, psychologists, legal advisors, municipal authorities, and teachers.

The strong growth of child protection services has triggered much debate about the effectiveness of educational and social care. As a result, a perspective change has been suggested, away from the traditional protection model, which deems children to be the sole responsibility of their parents, with the state offering only limited support to the parenting role, to a new welfare approach focused on children's and parents' participation. This participative paradigm sees interventions as user-led as much as service-driven, considering the children's and parents' viewpoint as crucial to ensure effective educational work (Lonne et al., 2009; Roose et al., 2009). Accordingly, families are seen by services as partners to be empowered when making critical decisions involving their lives, instead of problems to be "solved." This implies that practitioners should be able to acquire a more reflective stance on the families' perspectives in terms of meaning assigned by children and parents to the service's practices (Pease, 2002; Postle and Beresford, 2007; Ruch, 2005).

However, over the years, the requirements of bureaucratic work as well as the increase in practitioner numbers have contributed to a spread in the practice of report-writing in welfare agencies addressing the management of child protection (Hennum, 2011; Hummel, 1994; White et al., 2006). As a consequence, nowadays written documentation plays a core role in the process of managing cases of abused or maltreated children: every decision about the child is made on the basis of written reports derived from observations, interviews, and meetings aimed at building a visible history of the entire process through the collection of records. Therefore, reports actually have a strong influence on outcomes for children and families (Turney et al., 2012).

As we noted, in Italy, many child protection cases involve immigrant families and their children. Assuming that documentation is the production of a neutral and unbiased object, welfare services usually claim to adopt a fair and equal stance in treating immigrant and local children. However, in-depth analysis of the same documentation as a particular kind of "storytelling" about the child shows that services regularly use documents as an implicit way of defining what should be considered normal or deviant from the social and cultural point of view (Fairclough, 2003; Gillman et al., 1997; Salmon, 2010; Skehill et al., 2012).

Consequently, deconstructing the documentation work helps us to emphasize the central role that subjectivity and power play in orienting pivotal educational decisions concerning immigrant families and their children. To this end, we adopted a theoretical framework that refers to documents as (1) a discursive rite operating by "rules of exclusion" (Foucault, 1971; Garrity, 2010), (2) performative acts enabling forms of authoritative speech (Austin, 1979; Butler, 1993), and (3) milestones defining the "moral career" of children in social care (Goffman, 1961; Hall et al., 2006). This framework helps us to understand documentation as a twofold process both produced, i.e. creating a conceptual and terminological 
framework for organizational practices, and productive, i.e. building an image of organization as legitimate power (Atkinson and Coffey, 2011; Prior, 2008).

Accordingly, our research aims to answer these questions:

- Is the storytelling that is implied in case documentation leading practitioners to employ more reflective practices?

- How does documentation take into account cultural differences as a core feature in working with immigrant children and their families?

\section{Methodology}

The research focused on documentation offered by welfare services located in Northern Italy. Participants were selected purposely, as only two services out of seven gave permission to examine children's records. Documents related to eight child protection cases involving seven immigrant families (three from Morocco, two from Punjab, one from Nigeria, and one from Ghana). Two Morocco children (aged 12 and 15) were siblings. The ages of the children ranged from 4 to 15 . For each child, we examined the file containing all the records which describe, in chronological terms, the case development over time. Interventions ranged from a minimum of 10 months to a maximum of 5 years, and produced a large amount of documentation reaching, in one case, more than 100 documents written by different bodies and practitioners (Table 1).

All documents were stored in personal folders that accompany every child throughout the time he/she is taken responsibility for by protection services. Most documents were handwritten. They included both commissioned reports (namely juvenile court verdicts, medical records, psychological tests) and attendance notes in the form of social workers' accounts, youth workers' reports, and teachers' observations. In two cases, children's drawings had been added to the personal folders. We transcribed all the documents verbatim, paying attention to protecting the anonymity and privacy of children and practitioners in order to keep confidential all personal information concerning research participants. Case files translation to English was checked by a bilingual translator who regularly collaborates with the juvenile court.

Data were subsequently coded and analyzed through the interpretative phenomenological analysis (IPA) method (Smith et al., 2009). Based on the traditions of phenomenology, IPA is an experiential research methodology that explores individual cases and accounts by adopting a hermeneutical approach to data. IPA aims to recreate how individuals make meaning of the experiences they live through, both producing a detailed description of the participants' perspective and elaborating critical questions emerging from the materials investigated (Smith, 2011).

According to the IPA methodology, data analysis was carried out as following. Firstly, transcribed records were recursively analyzed by three independent 
Table I. Demographic data.

\begin{tabular}{llll}
\hline Country of origin & Children age & $\begin{array}{l}\text { Duration of } \\
\text { intervention (months) }\end{array}$ & $\begin{array}{l}\text { Documents } \\
\text { produced }\end{array}$ \\
\hline Ghana & 8 & 12 & 30 \\
Morocco & 4 & 23 & 25 \\
Morocco & 12 & 46 & 86 \\
Morocco & 15 & 61 & 112 \\
Nigeria & 8 & 10 & 18 \\
Punjab & 7 & 17 & 32 \\
Punjab & 12 & 30 & 51 \\
\hline
\end{tabular}

researchers to produce codes (first-level categories) and memos (personal notes about text and categories). Atlas- $t i^{\odot}$ software was employed to manage the coding activity and the following linkage among codes. As a verification procedure to check coding reliability (Miles et al., 2014), codes elicited by researchers were systematically compared to ensure inter-coder agreement $(k=0.89)$. Secondly, researchers established connections and relationships among codes that proved to be reliable, so developing emergent themes (or second level codes), which provided a higher level of abstraction, even though they still reflected the source material. Finally, emergent themes were selected and then grouped together according to conceptual similarities in order to create cloud views (Friese, 2014), i.e. conceptual categories that were used to produce the overall interpretation of data.

\section{Research findings}

The main findings of our research highlight five elements as especially relevant to understanding the services' documentation: agency, intertextuality, register, genre, and culture.

\section{Agency}

Different practitioners develop different relationships with the child and the documentation involving his/her case. The relationships can be described in terms of distance, knowledge, change, and evidence, as factors producing various forms of agency, which deeply influence the entire case management. As illustrated in Figure 1, a practitioners' activity can be classified according to the level of distance it implies from the child or the documentation. Youth workers typically work on the front lines, spending a large amount of time day and night with the child in order to provide support and assistance. Social workers and teachers also work with the child on a regular basis almost every day. Conversely, legal advisors and 


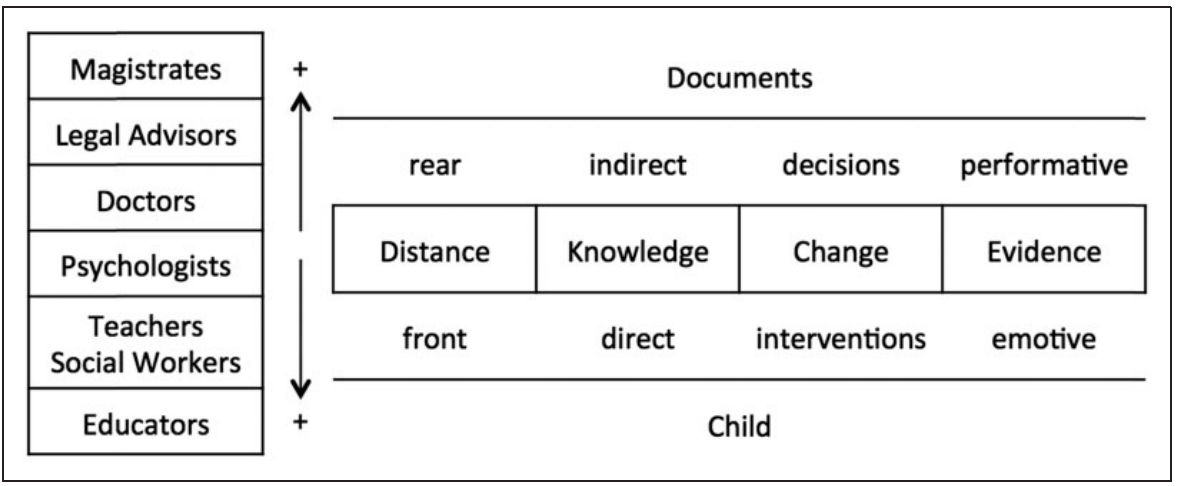

Figure I. Practitioners' levels of agency.

magistrates seldom meet the child in person, as their job is primarily based on the documentation provided by other practitioners following the case. In turn, doctors and psychologists see the child only for the time necessary for clinical assessment. Therefore, the level of knowledge ranges from first-hand observation deriving from direct contact with the child to indirect information achieved through the mediation of documentation. Consequently, the way agency is enacted varies accordingly: magistrates see change as decisions based on evidence described in deeply abstract and formalized documents. Paraphrasing Austin, verdicts "do things" as they are highly performative and powerful. One single sentence can have critical repercussions on the child's life course. On the opposite end of the spectrum, youth workers pursue change through interventions based on direct involvement of the child in everyday activities. Documents coming from this side are generally regarded as subjective, emotive, and therefore less reliable. As we will see, practitioners tend to compensate for the low "specific weight" of the documentation they produce, emphasizing even more the emotional component of their descriptions. In short, the less practitioners are "contaminated" by prolonged contact with the child, the more they have the power to make crucial decisions. However, decisions imply compliance from practitioners who have actual power in interventions and have first-hand information about the child, exactly because of prolonged contact. This recurrently exposes child protection services to serious risks of internal conflicts about what line of action should be adopted in managing cases.

\section{Intertextuality}

Documents are always interrelated in a twofold sense. Firstly, they keep the child and his/her parents as a shared reference throughout the piling up of different kinds of records (reports, projects, interviews, evaluations, etc.). However, the description offered by each document can be very different depending on the professional background (social, educational, legal, psychological, etc.). Consequently, the 


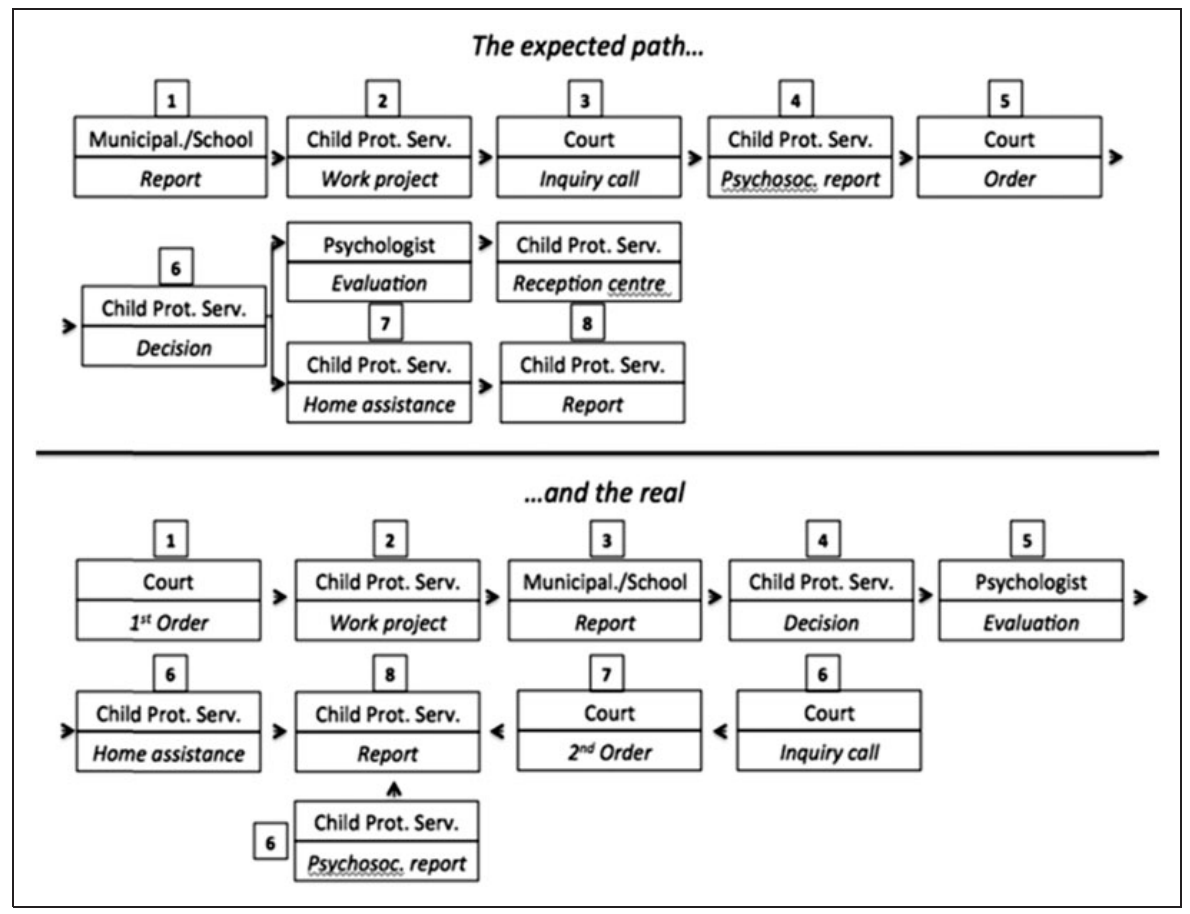

Figure 2. Expected and real decision path compared.

child's image is usually depicted as through a prism, which shows many facets but not a consistent, homogeneous picture. Secondly, documents refer to other documents, developing a "documentation trail," which seems to acquire an almost autonomous life, as far as records tend to demand and produce even more records. As a result, this intertextual process engenders both hierarchy, as documents confirm and strengthen the service's authority in enacting procedures that legitimate decisions about the child, and stratification, as such procedures can create an ambiguous and conflicting genealogy of choices. Figure 2 offers a typical example: the first flowchart on the upper part shows the guidelines that are assumed to define the decision path for managing children's admission to the reception center; the second flowchart is an example of the real path followed by practitioners during the admission procedure of one child. None of the eight cases we analyzed complied with the guidelines. When we asked service practitioners for an explanation, they confirmed that the same case can follow very different paths depending on the professional approach and reputation of the appointed practitioner, as well as on the way one record tends to steer the next step, emphasizing one issue rather than another. So, behind the outward neutrality of records, intertextuality discloses how values and power are deeply embedded in the "documentation game" that most practitioners play in order to put the case on what they assume should be the "right" path. 


\section{Register}

Despite documents being written by very different stakeholders, such as psychologists, legal advisors, and so on, reports tend to polarize into two separate registers. On the one hand, we find the "facts" style, aiming to produce detached and objective descriptions based on technical language. The resulting accounts are impersonal and decontextualized records, which emphasize a view of the child essentially as a measureable entity. Medical and psychological accounts are especially prone to the use of this kind of "scientific" language in order to create and classify cases. On the other hand, there is the "feelings" style, characterized by the production of emotionally loaded descriptions through language which refers (quite apparently) to a "moral" stance. These kinds of accounts emphasize colourful details and expressive remarks aimed at capturing the imagination of other practitioners and decision makers. However, being drawn up in official records contributes to lending legitimacy to such reports, framing them as factual and unbiased. Table 2 shows how these opposite styles are adopted to describe the same immigrant child. As a consequence, the resulting overall picture is fragmentary and even inconsistent in some ways as, for example, the child is depicted both as "overanxious to please" and "selfish."

\section{Genre}

As is known, narrative plays a key role in social and educational accounts (Bruner, 2003; Riessman and Quinney, 2005). Therefore, it is possible to trace in service documentation implicit references to well-known narrative genres, which shape the conceptual framework and vocabulary used by practitioners to describe the cases.

Table 2. Reports from child psychiatrist and youth workers.

\begin{tabular}{lc}
\hline Child psychiatrist's report & Youth workers's report \\
\hline $\begin{array}{c}\text { Cognitive functions are average for the age. } \\
\text { The WISC III scale reports the following }\end{array}$ & $\begin{array}{c}\text { He soon showed an inclination to be hasty and } \\
\text { a bit rough. Generally showing a selfish }\end{array}$ \\
scores: 98 IQ, VIQ and PIQ 93 I04. & attitude, according to which everything is \\
An analysis of the tests detects difficulties on & due to him, without ever keeping in mind \\
logical-deductive reasoning, attention to & that people other than him have needs too. \\
details, and visual acuity, which do not & Often indulges in attitudes that are too \\
impair the overall performance. & instinctual, proving to be a little rough and \\
He appears tense, distrustful, and overanxious & wild: scratching, always has a runny nose, \\
to please. & not tying his shoes, responds in a surly and \\
He is used to getting his own way, but with & $\begin{array}{l}\text { unfriendly way, shrugs, tumbles to the } \\
\text { low self-esteem and lack of emotional }\end{array}$ \\
investment toward the parental figures & $\begin{array}{l}\text { ground. From the point of view of hygiene, } \\
\text { there are many problems. }\end{array}$ \\
\hline
\end{tabular}

The WISC (Wechsler Intelligence Scale for Children) is an individually administered intelligence test for children (aged 6 to 16) commonly used by child psychologists and psychiatrists. 
Table 3. Reports from local health authority and teacher.

\begin{tabular}{|c|c|}
\hline Local health authority—clinical report & Teacher's report \\
\hline Name: Said & The child: \\
\hline Diagnosis: socio-cultural disadvantage & _ swears in class; \\
\hline $\begin{array}{l}\text { (individual with few/limited cognitive } \\
\text { skills) }\end{array}$ & $\begin{array}{l}\text { - overreacts to the comments of teachers } \\
\text { (screaming, tantrums, throwing objects, }\end{array}$ \\
\hline $\begin{array}{l}\text { Purpose: to acquire and strengthen basic } \\
\text { educational knowledge to facilitate } \\
\text { integration into the social and relational } \\
\text { environment }\end{array}$ & $\begin{array}{l}\text { verbal provocations, escape attempts); } \\
\text { _ } \quad \text { shows sudden outbursts of anger that lead } \\
\text { him to hurt himself or others; } \\
\text { _ }\end{array}$ \\
\hline $\begin{array}{l}\text { Objectives: to contain inattention and } \\
\text { emotional aspects }\end{array}$ & $\begin{array}{l}\text { scold me," "you do not wait for me", } \\
\text { "I want to die," "I can never"; }\end{array}$ \\
\hline Request: full-time teacher assistant & $\begin{array}{l}\text { - } \text { shows excessive food voracity; } \\
\text { - } \text { is careless with school supplies. } \\
\text { In terms of learning, the child proves to be } \\
\text { equipped with good skills, which have } \\
\text { allowed him to achieve satisfactory results }\end{array}$ \\
\hline
\end{tabular}

In turn, reports can be read as a kind of literary genre, whose roots rely on popular novels investigating the subject of deviance and otherness, a common topic in most Western literature. Accordingly, reports about immigrant children often refer to the contrast between civilization and wilderness. Most of records actually fit with the view of services as part of a bureaucratic machine, aiming to reinforce the stereotype of the child as a deviant individual in comparison with the expected standards. Like in Kafka's novels, the child's view on decisions involving his/her life is essentially irrelevant. Moreover, similar to Orwell's 1984, doublethink is in action: the clinical report in Table 2 (left) shows how the Local Health Authority assesses the case nonsensically, mixing, in just a few lines, sociocultural, cognitive, relational, and emotional features. Nevertheless, practitioners also describe immigrant children in terms of radical otherness, so reviving the well-grounded literary tradition which refers, for example, to the image of the "lost" or "feral" child depicted in Dickens' and Kipling's novels, respectively. The teacher's report in Table 3 (right) offers an example of this ambivalent view combining repulsion and attraction to the stranger, with the "wild" child surprisingly achieving "satisfactory results" in the end!

\section{Culture}

Understandably, practitioners involved in immigrant children's care are supposed to develop culturally sensitive work practices in order to deal effectively with ethnic diversity. According to Bennett (1993, 2004), cultural competences are acquired through a transition from an ethnocentric to ethnorelative attitude, following a five-step model that ranges from denial to polarization, minimization, acceptance, 
Table 4. Reports from psychologist and social worker.

\begin{tabular}{|c|c|}
\hline Psychologist's report & Social worker's report \\
\hline $\begin{array}{l}\text { Both parents come from Morocco. The } \\
\text { data collected and the clinical evalu- } \\
\text { ation show an avoidance/distancing } \\
\text { style of attachment. Mr.... in his } \\
\text { story reveals his own experience } \\
\text { connoted by detachment and loneli- } \\
\text { ness. He tells his life story: loss of } \\
\text { the father figure, the mother figure } \\
\text { caring, but busy working to maintain } \\
\text { the family. The account proceeds } \\
\text { with an emotionally detached atti- } \\
\text { tude. His own narrative, superficial, } \\
\text { lacking connections and emotionally } \\
\text { poignant memories, evokes an affec- } \\
\text { tively poor context and poor atten- } \\
\text { tion to personal growth }\end{array}$ & $\begin{array}{l}\text { Unlike her husband, who speaks fluently, the } \\
\text { mother has many difficulties with Italian. She is } \\
\text { probably illiterate in the language of origin. The } \\
\text { family has particularly tense relations with the } \\
\text { neighbors. The eldest son reports that two } \\
\text { years ago he had to show up at the Juvenile } \\
\text { Court for a complaint filed by a neighbour who, } \\
\text { he says, is racist. At the interview he turns up } \\
\text { with two friends, displaying a somewhat cocky } \\
\text { and arrogant attitude. He is clearly annoyed by } \\
\text { having to talk to a woman. During the interview, } \\
\text { he reports feeling particularly tense because of } \\
\text { his temporary unemployment. He often suffers } \\
\text { from migraines that sometimes cause nervous- } \\
\text { ness and loss of control. The youngest child } \\
\text { often comes to school wearing light clothing } \\
\text { despite the temperature outside, saying he does } \\
\text { not suffer from the cold. } \\
\text { The primary care physician reports that the two } \\
\text { children are much more independent than their } \\
\text { peers. This condition seems to be due to a } \\
\text { cultural factor and not to the lack of interest of } \\
\text { parents in their children }\end{array}$ \\
\hline
\end{tabular}

and adaptation. The documentation we analyzed shows that most practitioners, even though they are faced with cultural differences every day, are not automatically developing a higher level of intercultural sensitivity. Many of them remain in the denial phase, claiming to adopt a fair and equal stance simply by ignoring cultural differences and not taking culture into account as a relevant factor in their treatment of immigrant children and parents. This is especially the case with doctors and psychologists, whose advice is usually expressed through a panoply of supposedly neutral instruments such as diagnostic manuals or psychometric tests. Table 4 (left) shows an example of how a typically Western technical construct derived from attachment theory is used to assess a non-Western family. Other service practitioners seem to be more permeable to cultural elements, as they acknowledge that ethnicity plays a real role in managing immigrant families' cases. However, even though they prove to be more culturally sensitive, such consultants generally fall into the polarization category, which tends to essentialize cultural needs and experiences, and to see other cultures in terms of negative stereotypes. The example in Table 3 (right) shows how cultural misunderstandings due to gender stereotypes can deeply affect a professional interview. 


\section{Conclusions}

Our documentation analysis highlights that storytelling plays a key role in the way services handle immigrant children's protection. However, the practitioners' awareness of the narrative dimension of their working activities proved to be very limited in terms of developing more reflective practices and widening cultural sensitivity in managing cases. Nonetheless, our investigation also provides some suggestions about the way these professional shortcomings could be overcome, by furthering practitioners' abilities to reflect on their roles, fostering client empowerment through including the voices of immigrant children, and valuing cultural diversity as a resource instead of minimizing or dramatizing it. Below, we summarize these three areas for professional improvement:

- Practitioners' stance: we need to go beyond the still common view of practitioners as neutral experts, acknowledging them instead as "players in the game," i.e. as professionals who do not conceal or minimize their own biases, but assume them as a starting point for reflection (Baldwin, 2004; Ferguson, 2003). Reflection allows professionals to develop a critical approach to their practices over time, helping them develop a critical awareness of the factors that influence knowledge creation. On the one hand, it provides practitioners with a way of identifying their implicit assumptions and processing the issues from a different perspective. On the other, reflection enables professionals to analyze formal and informal knowledge generated from their own experience as practitioners, and how it fits with core values and the implications for practice (Fook and Gardner, 2007). Accordingly, promoting systematic and critical reflection would provide practitioners essential space to question both how knowledge about children's protection is generated and used, and how power relations influence the overall processes of managing individual cases;

- Reports' viewpoint: reflexivity should not to be limited to an in-depth analysis of professionals' perspective, but also requires taking into account the clients' view, accepting the complex challenges posed by the need to give a voice to immigrant children and their families (Maiter et al., 2006; Munn-Giddings and Winter, 2013). Enabling people who often have considerable communication problems due to their age or cultural background to have their voice heard in decisions about their future is paramount for ensuring the development of practice and service provision. Practitioners need to be more aware that child protection situations always involve a variety of views and perspectives. This implies an explicit commitment from professionals to ensuring that, although fragmented and powerless, the voices of those who are potentially or actually marginalized are consistently heard and taken into account (White et al., 2006). Consequently, seeking the genuine involvement of service users requires an analysis of power relationships embedded in documentation to ensure that clients' voices are really understood and valued; 
- Cultural differences: cultural diversity should neither be suppressed nor overemphasized in managing immigrant children's protection. Conversely, it must be valued as a crucial resource for expanding our ability to deal with difficult situations where ethnicity is a relevant factor. Facing cultural diversity requires specific skills relating to making sense of other people's lives, as providing effective help involves the ability to respond to the cultural dynamics of immigrant families (Engstrom and Okamura, 2007; Garran and Werkmeister Rozas, 2013). Such competence implies recognizing children's cultural backgrounds, respect for diversity as an element of professional self-awareness, and the ability to integrate these multifaceted features with helping skills (Ancis, 2004). Moreover, dealing with ethnicity requires practitioners to develop a proactive stance of challenging power imbalances that are concealed by bureaucratic approaches that mainly focus on individual interactions. When working in multicultural settings, professionals should become more sensitive to the way they simultaneously occupy "both oppressed and privileged positions, and that these positions intersect in complex ways" (Sensoy and DiAngelo, 2012: 115).

Finally, such improvements should be associated with concurrent reflection on the current use of documentation within welfare services. Too often documents are still employed as tools for "record wars" by practitioners who think their advice should prevail at all costs. A fair and equitable handling of immigrant children's cases also requires developing a deeper awareness that in documentation a polyphony of voices and democratic hermeneutics are requisite ingredients of effective professional practices.

\section{Declaration of Conflicting Interests}

The author declared no potential conflicts of interest with respect to the research, authorship, and/or publication of this article.

\section{Funding}

The author received no financial support for the research, authorship, and/or publication of this article.

\section{References}

Ancis J (ed) (2004) Culturally Responsive Interventions: Innovative Approaches to Working with Diverse Populations. New York, NY, Brunner-Routledge.

Atkinson PA and Coffey AJ (2011) Analysing documentary realities. In: Silverman D (ed.) Qualitative Research. London: Sage Publications, pp. 56-75.

Austin JL (1979) Performative utterances. Philosophical Papers 1: 233-252.

Baldwin M (2004) Critical reflection: Opportunities and threats to professional learning and service development in social work organizations. In: Gould N and Baldwin M (eds) Social Work, Critical Reflection and the Learning Organization. Aldershot: Ashgate, pp. 41-56.

Bennett MJ (1993) Towards ethnorelativism: A developmental model of intercultural sensitivity. In: Paige RM (ed.) Education for the Intercultural Experience. Yarmouth, ME: Intercultural Press, pp. 21-71. 
Bennett MJ (2004) Becoming interculturally competent. Toward Multiculturalism: A Reader in Multicultural Education 2: 62-77.

Bruner J (2003) Self-making narratives. In: Fivush R and Haden CA (eds) Autobiographical Memory and the Construction of a Narrative Self: Developmental and Cultural Perspectives. Mahwah, NJ: Lawrence Erlbaum, pp. 209-225.

Butler J (1993) Critically Queer. GLQ, A Journal of Lesbian and Gay Studies 1(1): 21.

Davies C and Ward H (2012) Safeguarding Children Across Services: Messages From Research. London: Jessica Kingsley.

Engstrom DW and Okamura A (2007) A nation of immigrants: A call for a specialization in immigrant well-being. Journal of Ethnic \& Cultural Diversity in Social Work 16(3-4): $103-111$.

Fairclough N (2003) Analysing Discourse: Textual Analysis for Social Research. London: Routledge.

Ferguson H (2003) Outline of a critical best practice perspective on social work and social care. British Journal of Social Work 33(8): 1005-1024.

Fook J and Gardner F (2007) Practising Critical Reflection: A Resource Handbook. Maidenhead: Open University Press/McGraw-Hill Education.

Foucault M (1971) The Archaeology of Knowledge. New York: Harper and Row.

Friese S (2014) Qualitative Data Analysis with Atlas.ti. London: SAGE Publications.

Garran AM and Werkmeister Rozas L (2013) Cultural competence revisited. Journal of Ethnic and Cultural Diversity in Social Work 22(2): 97-111.

Garrity Z (2010) Discourse analysis, Foucault and social work research: Identifying some methodological complexities. Journal of Social Work 10(2): 193-210.

Gillman M, Swain J and Heyman B (1997) Life history or "case" history: The objectification of people with learning difficulties through the tyranny of professional discourses. Disability \& Society 12(5): 675-694.

Goffman E (1961) Asylums. New York: Double Day.

Hall C, Slembrouck S and Sarangi S (2006) Language Practices in Social Work: Categorisation and Accountability in Child Welfare. London: Routledge.

Hennum N (2011) Controlling children's lives: Covert messages in child protection service reports. Child and Family Social Work 16(3): 336-344.

Hummel RP (1994) The Bureaucratic Experience: A Critique of Life in the Modern Organization. New York: St Martin's Press.

Lonne B, Parton N, Thomson J, et al. (2009) Reforming Child Protection. London: Routledge.

Maiter S, Palmer S and Manji S (2006) Strengthening social worker-client relationships in child protective services addressing power imbalances and 'ruptured' relationships. Qualitative Social Work 5(2): 161-186.

Miles MB, Huberman MA and Saldaña J (2014) Qualitative Data Analysis: A Methods Sourcebook. London: SAGE Publications.

Munn-Giddings C and Winter R (2013) A Handbook for Action Research in Health and Social Care. London: Routledge.

Pease B (2002) Rethinking empowerment: A postmodern reappraisal for emancipatory practice. British Journal of Social Work 32(2): 135-147.

Postle K and Beresford P (2007) Capacity building and the reconception of political participation: A role for social care workers? British Journal of Social Work 37(1): 143-158.

Prior L (2008) Repositioning documents in social research. Sociology 42(5): 821-836. 
Riessman CK and Quinney L (2005) Narrative in social work. Qualitative Social Work 4(4): 391-412.

Roose R, Mottart A, Dejonckheere N, et al. (2009) Participatory social work and report writing. Child \& Family Social Work 14(3): 322-330.

Ruch G (2005) Relationship-based practice and reflective practice: Holistic approaches to contemporary child care social work. Child and Family Social Work 10(2): 111-123.

Salmon C (2010) Storytelling: Bewitching the Modern Mind. London: Verso.

Sensoy Ö and DiAngelo R (2012) Is Everyone Really Equal? An Introduction to Key Concepts in Social Justice Education. New York, NY: Teachers College Press.

Sethi S, Bellis M, Hughes K, et al. (2013) European Report on Preventing Child Maltreatment. Copenhagen: WHO.

Skehill C, Satka M and Hoikkala S (2012) Exploring innovative methodologies in time and place to analyse child protection documents as elements of practice. Qualitative Social Work 12(1): 57-72.

Smith JA (2011) Evaluating the contribution of interpretative phenomenological analysis. Health Psychology Review 5(1): 9-27.

Smith JA, Flowers P and Larkin M (2009) Interpretative Phenomenological Analysis: Theory Method and Research. London: Sage Publications.

Turney D, Platt D, Selwyn J, et al. (2012) Improving Child and Family Assessments: Turning Research into Practice. London: Jessica Kingsley.

White S, Fook J and Gardner F (2006) Critical Reflection in Health and Social Care. Maidenhead: Open University Press/McGraw-Hill Education. 